\title{
Effects of Hydrogen Peroxide on Organically Fertilized Hydroponic Lettuce (Lactuca sativa L.)
}

\author{
Vanessa Lau ${ }^{1 *}$, Neil Mattson ${ }^{2}$ \\ 1 School of Integrative Plant Sciences, Cornell University, Ithaca, NY 14853; vml44@cornell.edu \\ 2 School of Integrative Plant Sciences, Cornell University, Ithaca, NY 14853; nsm47@cornell.edu \\ * Correspondence: vml44@cornell.edu; Tel.: +1 786-381-2227
}

\begin{abstract}
Hydroponic production typically uses conventional fertilizers and information is lacking on the use of organic hydroponic fertilizers. Development of biofilm is a common problem with organic hydroponics which can reduce dissolved oxygen availability to roots. One potential solution is the use of hydrogen peroxide, $\mathrm{H}_{2} \mathrm{O}_{2}$ which can reduce microbial populations and decomposes to form oxygen. However, information is lacking on the impact of hydrogen peroxide on hydroponic crops. The aim of this study was to determine the effects of $\mathrm{H}_{2} \mathrm{O}_{2}$ concentrations in deep water culture hydroponics by assessing how it affects plant size and yield in lettuce (Lactuca sativa L.) 'Rouxai' . In this experiment, three different treatments consisting of a control without $\mathrm{H}_{2} \mathrm{O}_{2}$, and the application of $37.5 \mathrm{mg} / \mathrm{L}$ or $75 \mathrm{mg} / \mathrm{L}$ of hydrogen peroxide were added to aerated 4-L reservoirs that contained either organic (4-4-1) or inorganic nutrients (21-5-20), both applied at $150 \mathrm{mg} \cdot \mathrm{L}^{-1} \mathrm{~N}$. Three replicates for each treatment and each fertilizer were prepared resulting in a total of eighteen mini hydroponic containers each with one head of lettuce. When added to conventional fertilizers, concentrations of $37.5 \mathrm{mg} / \mathrm{L}$ and $75 \mathrm{mg} / \mathrm{L}$ of $\mathrm{H}_{2} \mathrm{O}_{2}$ led to stunted growth or death lettuce plants. However, when $37.5 \mathrm{mg} / \mathrm{L}$ of $\mathrm{H}_{2} \mathrm{O}_{2}$ was applied to organic fertilizers, the lettuce yield nearly matched that of the conventionally fertilized control, demonstrating that the application of $\mathrm{H}_{2} \mathrm{O}_{2}$ has the potential to make organic hydroponic fertilization a more viable method in the future.
\end{abstract}

Keywords: hydroponics; organic; biofilm; hydrogen peroxide; fertilizer

\section{Introduction}

Marketed as a technologically revolutionary and sustainable way to grow produce, the employment of hydroponic methods in greenhouses and "plant factories" is gaining traction globally [1]. However, chemical fertilizers typically used in hydroponics are mined from nonrenewable, finite sources or rely on fossil fuels for production rendering them unsustainable [2,3]. Moreover, the disposal of chemically-fertilized waste water from these systems can leach into the environment and over time, degrade ecosystems as well as contaminate clean water sources $[4,5]$.

An alternative to these conventional fertilizers is the use of organic fertilizers from plant and animal byproducts such as seaweed extract, manure, or hydrolyzed fish emulsion [6] which require the development of microbial communities to mineralize complex organic compounds to make them plant available [7,8]. Drawbacks of organic fertilizers include variable, significantly reduced yield [911] which may be attributed to: unstable microbial activity, difficulty supplying the proper proportion of nutrients, high $\mathrm{pH}$ as well as the development of biofilm in the organically fertilized hydroponic reservoirs [12]. Regarding biofilm, it is believed that the suspended organic matter, which can develop on plant roots as well as clog pumps/recirculation lines, reduce oxygen and nutrient uptake by roots as well as deplete oxygen levels [13-15]. 
There is some anecdotal evidence that the addition of hydrogen peroxide $\left(\mathrm{H}_{2} \mathrm{O}_{2}\right)$ to organically fertilized reservoirs may help reduce the development of biofilm and improve performance of organic hydroponics [16,17]. $\mathrm{H}_{2} \mathrm{O}_{2}$ is an unstable oxidizing agent most commonly used as an inexpensive, household disinfectant and bleaching agent [18]. Byproducts produced by the decomposition of $\mathrm{H}_{2} \mathrm{O}_{2}$ are $\mathrm{H}_{2} \mathrm{O}$ and $\mathrm{O}_{2}$. The released $\mathrm{O}_{2}$ can increase the dissolved oxygen concentration in the root zone and may also help reduce oxygen losses to biofilm and microbial respiration. Though the application of $\mathrm{H}_{2} \mathrm{O}_{2}$ is thought to help increase $\mathrm{DO}$ concentrations within the reservoir, in conventional hydroponics lettuce studies did not previously show a positive benefit of DO at or above $25 \%$ of saturation $\left(2.1 \mathrm{mg} \cdot \mathrm{L}^{-1}\right)$ on shoot or root biomass [19]. Possible benefits of $\mathrm{H}_{2} \mathrm{O}_{2}$ in an organic hydroponic system could be to increase dissolved oxygen concentration if they fall below this low threshold or alternatively may be due to $\mathrm{H}_{2} \mathrm{O}_{2}$ 's disinfectant properties.

However, currently there is no work in the scientific literature on $\mathrm{H}_{2} \mathrm{O}_{2}$ use in conventional or organic hydroponic systems, including no commonly recognized concentration or range of $\mathrm{H}_{2} \mathrm{O}_{2}$ to add to hydroponic systems. Excess $\mathrm{H}_{2} \mathrm{O}_{2}$ can also harm plant root systems in hydroponics $[16,20,21]$ and information is lacking on the concentration that damages hydroponic crops, including lettuce. Currently suggested $\mathrm{H}_{2} \mathrm{O}_{2}$ practices vary greatly among hobbyists and are typically determined on a trial and error basis. With little to no scientifically backed information available on the topic, this study aims to explore the usage of $\mathrm{H}_{2} \mathrm{O}_{2}$ on dissolved oxygen in the root zone and its effects on yield in conventionally and organically fertilized lettuce heads.

\section{Materials and Methods}

\subsection{Experimental Seedling Preparation}

The experiments were conducted at the Cornell University Kenneth Post Laboratory greenhouses in Ithaca, New York at room temperature $\left(22^{\circ} \mathrm{C}\right)$ with ambient lighting, with the first crop cycle taking place from November through December 2018 and the second crop cycle taking place March to April 2019. A flat with $1.5 \times 1.5$ inch rockwool plugs was soaked in reverse osmosis water for approximately 10 minutes and then was drained and placed on a plastic flat. Each rockwool cell was seeded with one pelleted (Lactuca sativa L.) 'Rouxai' seed (Johnny's Seeds, Fairfield, ME) and was allowed to germinate in a seedling production area in the greenhouse under 18-hour lighting from high pressure sodium (HPS) lamps. The seedlings were watered daily with fertilized water (Jack's Professional LX 21-5-20 All Purpose Water-Soluble Fertilizer supplemented with magnesium sulfate so as to supply $30 \mathrm{ppm} \mathrm{Mg}$ ). Seedlings were transplanted into 4-L hydroponic containers after 21 days.

\subsection{Treatment Setup}

After 21 days when the seedlings had 3 to 4 true leaves, eighteen individual 4-L buckets were prepared for the experiment. Each bucket was filled near to capacity with reverse osmosis water. The conventional fertilizer, Jack's Professional LX 21-5-20 All Purpose Water-Soluble Fertilizer (JR Peters Inc., Allentown, PA) with magnesium sulfate was applied to half of the buckets, the other half of the buckets were fertilized with the organic fertilizer, Drammatic One 4-4-1 Fish Emulsion (Dramm Corporation, Manitowoc, WI) and in both cases the fertilizers were added to supply an electrical conductivity (EC) of 1.5-1.7 dS/m. $\mathrm{H}_{2} \mathrm{O}_{2}$ was added to the buckets according to the treatments in Table 1 to create 3 replications of each treatment. 
bioRxiv preprint doi: https://doi.org/10.1101/2021.01.01.425018; this version posted January 4,2021 . The copyright holder for this preprint (which was not certified by peer review) is the author/funder, who has granted bioRxiv a license to display the preprint in perpetuity. It is made available under aCC-BY-NC-ND 4.0 International license.

Table 1. Names and descriptions of experimental treatments

\begin{tabular}{cc}
\hline Treatment & Description \\
\hline CONV_0 & Conventionally fertilized control \\
CONV_37.5 & Conventionally fertilized with $37.5 \mathrm{mg} / \mathrm{L} \mathrm{H}_{2} \mathrm{O}_{2}$ \\
CONV_75 & Conventionally fertilized with $75 \mathrm{mg} / \mathrm{L} \mathrm{H}_{2} \mathrm{O}_{2}$ \\
ORG_0 & Organically fertilized control \\
ORG_37.5 & Organically fertilized with $37.5 \mathrm{mg} / \mathrm{L} \mathrm{H}_{2} \mathrm{O}_{2}$ \\
ORG_75 & Organically fertilized with $75 \mathrm{mg} / \mathrm{L} \mathrm{H}_{2} \mathrm{O}_{2}$ \\
\hline
\end{tabular}

The buckets were arranged on a bench in the greenhouse in 3 rows of 6 buckets spaced approximately $30 \mathrm{~cm}$ apart and each bucket was individually aerated with an airstone placed near the rootzone that was powered by air pumps (GH2716, General Hydroponics, Santa Rosa, CA) as shown in Figure 1 and were randomly arranged by treatment.

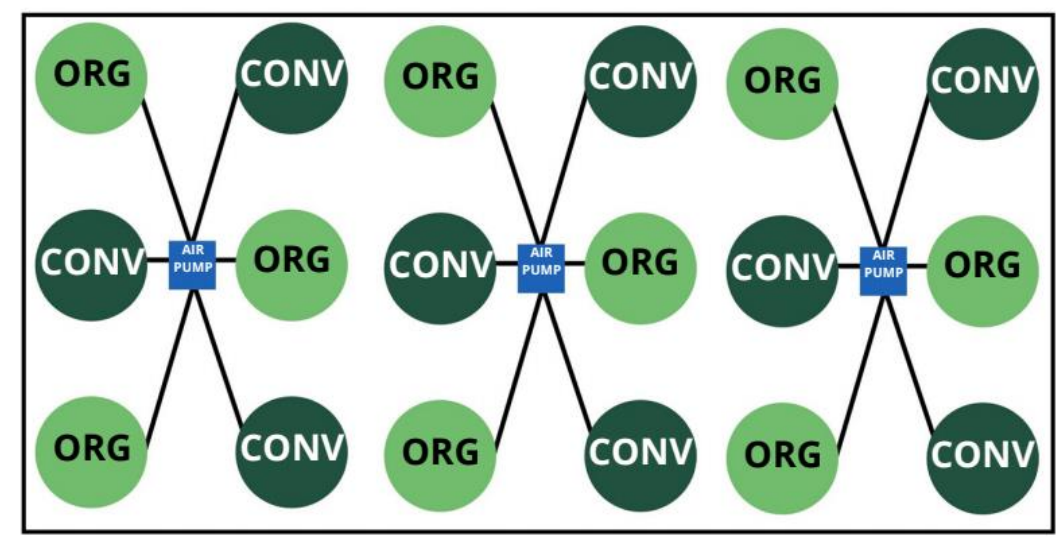

Figure 1. Illustration of experimental set up

The electrical conductivity (EC) of each bucket was measured using an EcoTestr CTS meter (Oakton, Vernon Hills, IL) and was adjusted to $1.5-1.7 \mathrm{dS} / \mathrm{m}$. Additionally, the $\mathrm{pH}$ levels were measured using an EcoTestr pH2+ meter (Oakton, Vernon Hills, IL) and were adjusted to 5.5-6 with either nitric acid $\left(1 \mathrm{M} \mathrm{HNO}_{3}\right)$ to lower the $\mathrm{pH}$ or potassium hydroxide $(1 \mathrm{M} \mathrm{KOH})$ to bring $\mathrm{pH}$ levels up.

18 uniform lettuce seedlings were selected from the seedling production area and each plant was placed in the 1" diameter hole drilled into the center of each lid so that the rockwool plugs fit snugly. The buckets were checked to make sure the water levels were high enough to reach the plants' roots. Dissolved oxygen (DO) measurements were taken using a YSI Pro20 Dissolved Oxygen Meter (Xylem Inc., Yellow Springs, $\mathrm{OH}$ ) and results are expressed on a percent of DO saturation at the recorded water temperature.

\subsection{Experimental Protocol \& Data Collection}

Each day, EC and $\mathrm{pH}$ were adjusted and maintained between the target values $(1.5-1.7 \mathrm{dS} / \mathrm{m}$ and $\mathrm{pH}$ 5.5-6) using the respective tools and reservoir water levels were topped-off daily to maintain 4- $\mathrm{L}$ of nutrient solution. DO measurements were recorded daily. 
Every 3 days, hydrogen peroxide was replenished according to the treatment prior to the DO measurements for that day. This was done for 17 days and on the 18th, lettuce was harvested by severing the plant where the plant stalk met the rockwool plugs and final fresh weight was recorded.

\section{Results}

\subsection{Dissolved Oxygen}

In the Fall trial, dissolved oxygen (DO) levels were recorded each day to track the degradation of $\mathrm{H}_{2} \mathrm{O}_{2}$ within the rootzone. DO was added to the hydroponic containers 3 times weekly (represented by days $0,3,6,12,15 \ldots$ ) on Figure 2 . Steep increases in DO levels typically represent days in which $\mathrm{H}_{2} \mathrm{O}_{2}$ was added to the reservoirs. It was noted that on average, organically fertilized treatments saw more drastic swings in DO levels than their conventional counterparts and that over time, the application of $\mathrm{H}_{2} \mathrm{O}_{2}$ had lessened effects on DO levels. Conventional fertilizer with $75 \mathrm{mg} / \mathrm{L} \mathrm{H}_{2} \mathrm{O}_{2}$ led to the greatest sustained levels of $\mathrm{DO}$, in the organic treatments DO level degraded more quickly after each addition.

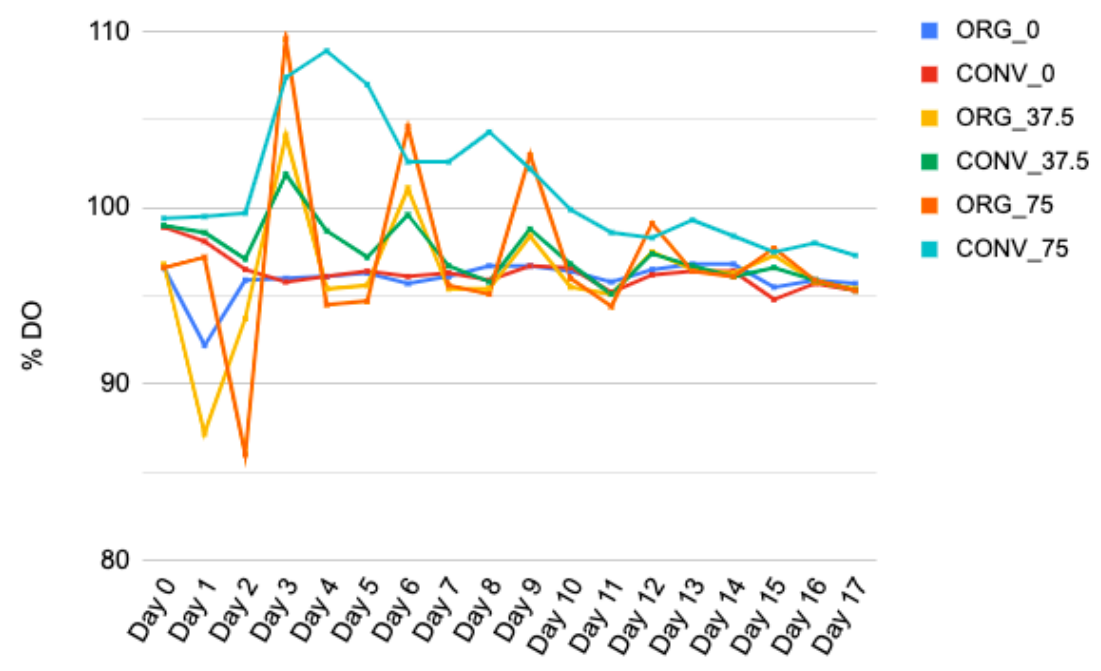

Figure 2. Percent dissolved oxygen levels taken within lettuce plant root zones in the fertilizer and $\mathrm{H}_{2} \mathrm{O}_{2}$ treatments in the Fall trial. Data are means of 3 plants per treatment combination per day.

\subsection{Fresh Weight}

The plants in the CONV_0 treatment had the highest mean value, with no statistically significant difference between this treatment and organic or conventional treatments with 37.5 $\mathrm{mg} / \mathrm{L} \mathrm{H}_{2} \mathrm{O}_{2}$ (Figure 3). The conventionally fertilized control yield was nearly double that of the organically fertilized with $0 \mathrm{mg} / \mathrm{L} \mathrm{H}_{2} \mathrm{O}_{2}$. With the lower application of $\mathrm{H}_{2} \mathrm{O}_{2}$, however, ORG_37.5 had a statistically similar FW as CONV_37.5 and CONV_0. At the greater application of $75 \mathrm{mg} / \mathrm{L}$ $\mathrm{H}_{2} \mathrm{O}_{2}$, both ORG_75 and CONV_75 yield decreased with the CONV_75 plants dying and therefore having a lower FW than all other treatments. Across treatments, this shows that application of $\mathrm{H}_{2} \mathrm{O}_{2}$ had a negative impact on CONV but low doses $(37.5 \mathrm{mg} / \mathrm{L})$ actually increased yield of organic treatments to the point that it was not significantly different from conventional fertilizer.

During the Spring 2019 trial, trends between treatments remained similar confirming the results from the Fall 2018 trial (Figure 3). However, overall fresh weight was greater in the Spring trial due to greater ambient light. Additionally, though their growth was severely stunted, the plants grown with the CONV_75 and ORG_75 treatments with high doses of $\mathrm{H}_{2} \mathrm{O}_{2}$ did not die. 


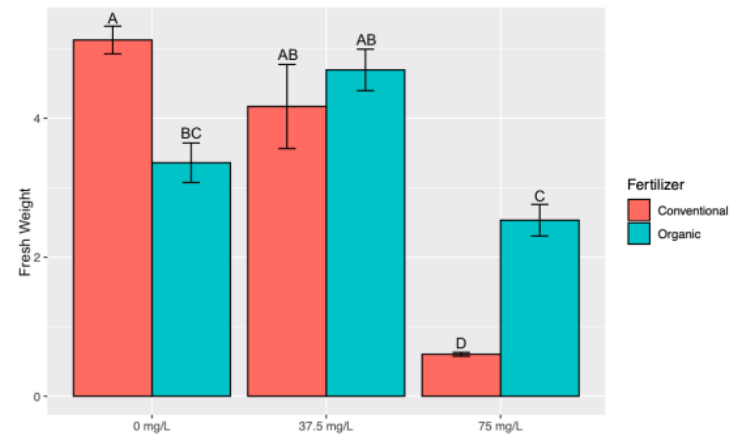

(a)

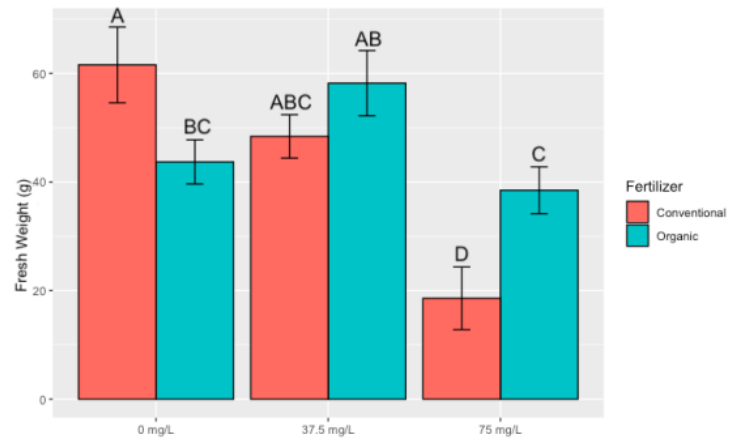

(b)

Figure 3. Fresh weight in grams of lettuce plants in response to organic and conventional fertilizer and addition of $\mathrm{H}_{2} \mathrm{O}_{2}$ in the Fall (a) and Spring (b) trial. Data are means \pm SE of 3 plants per treatment combination. Letters represent mean separation comparison using Tukey's HSD (alpha $=0.05$ ).

\subsection{Root Length}

In the Fall trial plants in the CONV_0 and ORG_0 treatment had the highest mean root length (Figure 4). The application of $\mathrm{H}_{2} \mathrm{O}_{2}$ dramatically decreased root length for both fertilizer treatments but the effects were more dramatic for conventionally fertilized treatments.

In the Spring trial similar patterns were found. There was no difference in root length between the conventional and organic controls, but as $\mathrm{H}_{2} \mathrm{O}_{2}$ treatments increased, root length dramatically decreased, especially in the conventionally fertilized treatments.

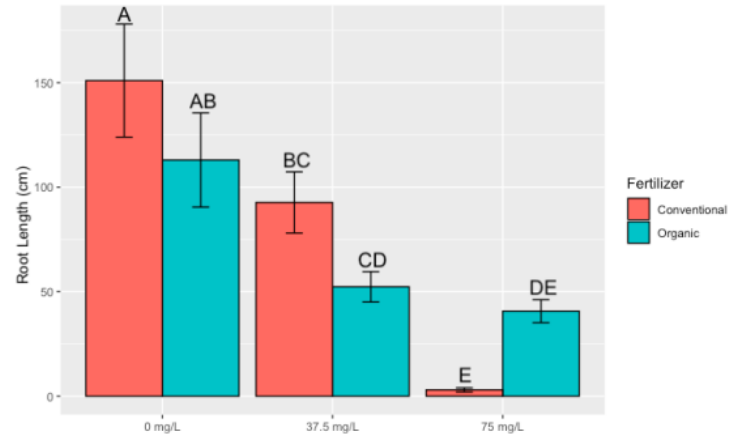

(a)

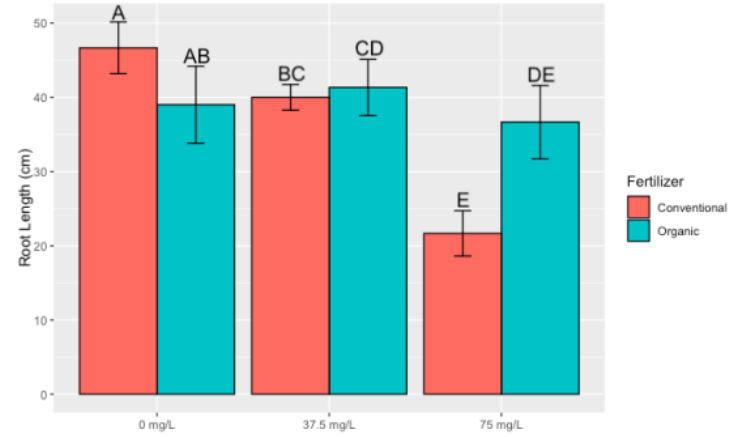

(b)

Figure 4. Root length of lettuce plants in response to organic and conventional fertilizer and addition of hydrogen peroxide in the Fall (a) and Spring (b) trial. Data are means \pm SE of 3 plants per treatment combination. Letters represent mean separation comparison using Tukey's HSD (alpha $=0.05)$.

\subsection{Leaf Width and Plant Height}

For the Fall trial, data was collected on leaf width and plant height. Due to time constraints these parameters were not collected in the Spring trial. For leaf width, the only statistically significant difference was that CONV_75 had a smaller leaf width (about half the size) as all other treatments (Figure 5). 


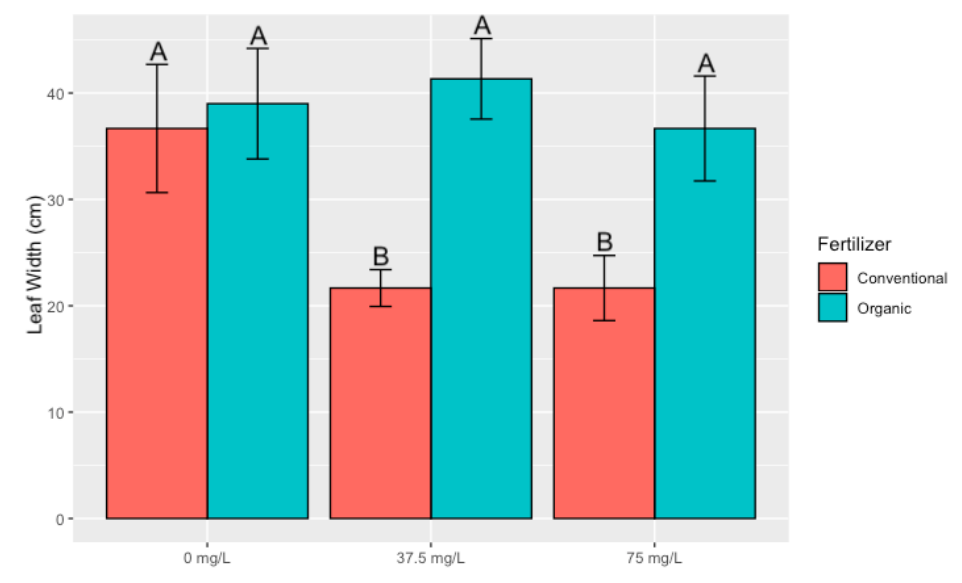

Figure 5. Leaf width of lettuce plants in response to organic and conventional fertilizer and addition of hydrogen peroxide in the Fall trial. Data are means \pm SE of 3 plants per treatment combination. Letters represent mean separation comparison using Tukey's HSD (alpha=0.05).

Likewise, for plant height, similar trends were found whereby height of conventionally fertilized plants at $75 \mathrm{mg} / \mathrm{L} \mathrm{H}_{2} \mathrm{O}_{2}$ was dramatically smaller than other treatments. For organic fertilization, the plants at $75 \mathrm{mg} / \mathrm{L} \mathrm{H}_{2} \mathrm{O}_{2}$ were shorter than conventional plants at $37.5 \mathrm{mg} / \mathrm{L} \mathrm{H}_{2} \mathrm{O}_{2}$ (Figure 5).

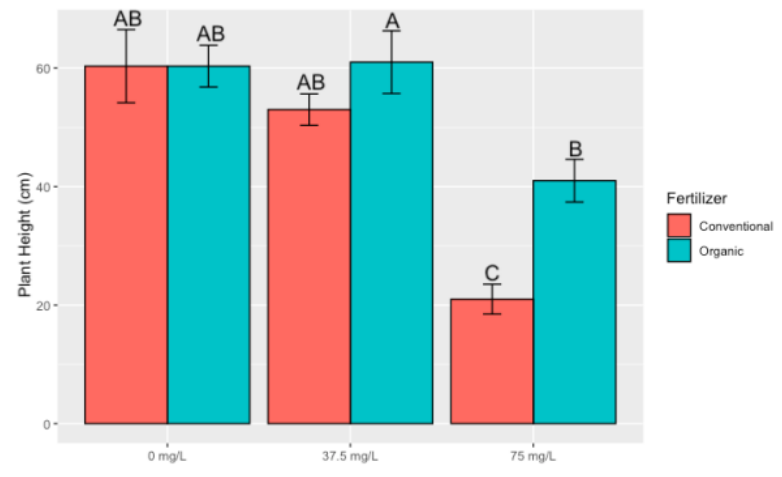

Figure 6. Plant height of lettuce plants in response to organic and conventional fertilizer and addition of hydrogen peroxide in the Fall trial. Data are means \pm SE of 3 plants per treatment combination. Letters represent mean separation comparison using Tukey's HSD (alpha=0.05).

\section{Discussion}

The results of this study show the potential for the integration of $\mathrm{H}_{2} \mathrm{O}_{2}$ with organic fertilizers to optimize hydroponic lettuce yield. Without hydrogen peroxide, our study found that organic fertilization performed poorer (fresh weight, root length) than conventional fertilizer. Our findings with organic fertilization performance (without $\mathrm{H}_{2} \mathrm{O}_{2}$ ) are similar to those reported by Atkin \& Nichols [11]. For example, Atkin \& Nichols also tested hydrolyzed fish emulsion based fertilizer and found that organic hydroponic lettuce had approximately $55 \%$ lower fresh weight than conventional. Results from the conventional and organic controls matched the \% yield ranges of other studies $[11,22,23]$

$\mathrm{H}_{2} \mathrm{O}_{2}$ additions reduced the performance of conventionally fertilized plants. $\mathrm{H}_{2} \mathrm{O}_{2}$ works by decomposing into an unstable free radical oxygen molecule which can destroy biotic cell tissue. As such, $\mathrm{H}_{2} \mathrm{O}_{2}$ has the potential to indiscriminately damage healthy living root tissue, consequently reducing fresh weight of lettuce heads in higher doses. Root damage may be the result of this phytotoxicity $[24,25,26]$. However, when $\mathrm{H}_{2} \mathrm{O}_{2}$ at $37.5 \mathrm{mg} / \mathrm{L}$ was added to organic fertilizer the organic 
fertilizer performed as well as conventional fertilizer without $\mathrm{H}_{2} \mathrm{O}_{2}$. Whereas $\mathrm{H}_{2} \mathrm{O}_{2}$ at $37.5 \mathrm{mg} / \mathrm{L}$ or 75 $\mathrm{mg} / \mathrm{L}$. We hypothesize that the lack of negative impacts of $1.25 \mathrm{~mL} / \mathrm{L} \mathrm{H}_{2} \mathrm{O}_{2}$ in the organic fertilizer treatment were due to the effect of biofilm present in the rootzone - the free radical oxygen molecules may have disrupting biofilm matter thereby leading to less damage to roots. Since the conventionally fertilized reservoirs did not contain visible biofilm, this may have led to higher levels of root damage, and subsequently, lower lettuce fresh weight.

Moreso, while the effects of the application of $\mathrm{H}_{2} \mathrm{O}_{2}$ had a visible impact on the plant material, there were no visible reductions in biofilm development among the organic treatments. This indicates that while it may be effective in increasing yield, manual disinfection of hydroponic systems would still be needed in between growth cycles to clear out the biofilm that may clog and stick to surfaces. Though future research would be needed to quantify the impact of $\mathrm{H}_{2} \mathrm{O}_{2}$ on biofilm in hydroponics.

\section{Conclusions}

Overall it was found that the use of $37.5 \mathrm{mg} / \mathrm{L} \mathrm{H}_{2} \mathrm{O}_{2}$ could lead to effective performance of plants receiving organic hydroponics. More research is needed to determine if the response is due to 1) the increase in dissolved oxygen content of the root-zone as $\mathrm{H}_{2} \mathrm{O}_{2}$ disassociated, 2) the effects of $\mathrm{H}_{2} \mathrm{O}_{2}$ on biofilm development (i.e. injuring biofilm but allowing for greater nutrient or dissolved oxygen access by roots), or 3 ) the effect of $\mathrm{H}_{2} \mathrm{O}_{2}$ on the chemical makeup (nutrient availability) or the organic hydroponic nutrient solution. Future research should seek to understand the optimum concentration and reapplication rate of $\mathrm{H}_{2} \mathrm{O}_{2}$ in organic hydroponic fertilization and well as to understand the mechanism for the response so that we have a greater understanding of effective organic hydroponic fertilization strategies.

Author Contributions: Conceptualization, V.L.; methodology, V.L. and N.M.; formal analysis, V.L. and N.M..; writing-original draft preparation, V.L.; writing-review and editing, N.M.; supervision, N.M.; project administration, N.M. All authors have read and agreed to the published version of the manuscript.

Funding: This research was funded by the Rawlings Cornell Presidential Research Scholarship and the Ronald E. McNair Post Baccalaureate Achievement Program.

Acknowledgments: I wish to express my sincere gratitude to Matthew Moghaddam and Nicholas Kaczmar for their valuable technical support. Without their assistance, this paper and the research behind it would not have been possible.

Conflicts of Interest: The authors declare no conflict of interest.

\section{References}

1. Jensen, Merle H. “Hydroponics Worldwide.” Acta Horticulturae, no. 481 (January 1999): 719-30.

2. Nichols, M.A., and N.A. Savidov. "Aquaponics: A Nutrient and Water Efficient Production System." Acta Horticulturae, no. 947 (May 2012): 129-32.

3. Scholz, Roland W., Andrea E. Ulrich, Marjatta Eilittä, and Amit Roy. "Sustainable Use of Phosphorus: A Finite Resource." Science of The Total Environment 461-462 (September 1, 2013): 799-803.

4. Kumar, Ramasamy Rajesh, and Jae Young Cho. "Reuse of Hydroponic Waste Solution." Environmental Science and Pollution Research 21, no. 16 (August 1, 2014): 9569-77.

5. Bertoldi, F.C., E. Sant'Anna, and J.L. Barcelos-Oliveira. “Chlorella Vulgaris Cultivated in Hydroponic Wastewater." Acta Horticulturae, no. 843 (October 2009): 203-10.

6. Treadwell, Danielle D., George J. Hochmuth, Robert C. Hochmuth, Eric H. Simonne, Lei L. Davis, Wanda L. Laughlin, Yuncong Li, Teresa Olczyk, Richard K. Sprenkel, and Lance S. Osborne. "Nutrient Management in Organic Greenhouse Herb Production: Where Are We Now?" HortTechnology 17, no. 4 (January 1, 2007): 461-66. 
7. Shinohara, Makoto, Chihiro Aoyama, Kazuki Fujiwara, Atsunori Watanabe, Hiromi Ohmori, Yoichi Uehara, and Masao Takano. "Microbial Mineralization of Organic Nitrogen into Nitrate to Allow the Use of Organic Fertilizer in Hydroponics." Soil Science and Plant Nutrition 57, no. 2 (April 1, 2011): 190-203.

8. Kawamura-Aoyama, Chihiro, Kazuki Fujiwara, Makoto Shinohara, and Masao Takano. "Study on the Hydroponic Culture of Lettuce with Microbially Degraded Solid Food Waste as a Nitrate Source." Japan Agricultural Research Quarterly: JARQ 48, no. 1 (2014): 71-76. https://doi.org/10.6090/jarq.48.71.

9. Tikasz, Peter, Sarah MacPherson, Viacheslav Adamchuk, and Mark Lefsrud. “Aerated Chicken, Cow, and Turkey Manure Extracts Differentially Affect Lettuce and Kale Yield in Hydroponics." International Journal of Recycling of Organic Waste in Agriculture 8, no. 3 (September 1, 2019): 241-52.

10. Zandvakili, Omid R., Allen V. Barker, Masoud Hashemi, Fatemeh Etemadi, and Wesley R. Autio. "Comparisons of Commercial Organic and Chemical Fertilizer Solutions on Growth and Composition of Lettuce." Journal of Plant Nutrition 42, no. 9 (May 28, 2019): 990-1000.

11. Atkin, K., and M.A. Nichols. “Organic Hydroponics.” Acta Horticulturae, no. 648 (February 2004): 121-27.

12. Williams, K.A., and J.S. Nelson. "Challenges of Using Organic Fertilizers in Hydroponic Production Systems." Acta Horticulturae, no. 1112 (March 2016): 365-70.

13. Li, Shuqing, Nan Zhang, Zhenhua Zhang, Jia Luo, Biao Shen, Ruifu Zhang, and Qirong Shen. "Antagonist Bacillus Subtilis HJ5 Controls Verticillium Wilt of Cotton by Root Colonization and Biofilm Formation." Biology and Fertility of Soils 49, no. 3 (April 1, 2013): 295-303.

14. Fujiwara, Kazuki, Chihiro Aoyama, Masao Takano, and Makoto Shinohara. "Suppression of Ralstonia Solanacearum Bacterial Wilt Disease by an Organic Hydroponic System." Journal of General Plant Pathology 78, no. 3 (May 1, 2012): 217-20.

15. Elasri, Mohamed O., and Robert V. Miller. "Study of the Response of a Biofilm Bacterial Community to UV Radiation." Applied and Environmental Microbiology 65, no. 5 (May 1, 1999): 2025-31.

16. Jason's Guide to Organic and Hydroponic Gardening. Available online: https://www.jasons-indoor-guideto-organic-and-hydroponics-gardening.com/using-hydrogen-peroxide.html (accessed on 23 January 2019).

17. Green and Vibrant. Available online: https://www.trees.com/gardening-and-landscaping/hydrogenperoxide-hydroponics (accessed on 23 January 2019).

18. Watt, Barbara E., Alex T. Proudfoot, and J. Allister Vale. "Hydrogen Peroxide Poisoning." Toxicological Reviews 23, no. 1 (March 1, 2004): 51-57.

19. Goto, E., Both, A., Albright, L., Langhans, R., \&amp; Leed, A. “Effect Of Dissolved Oxygen Concentration On Lettuce Growth In Floating Hydroponics.” Acta Horticulturae, no. 440 (1996): 205-210.

20. Science in Hydroponics. Available online: https://scienceinhydroponics.com/2009/02/using-hydrogenperoxide-in-hydroponic-crops.html (accessed on 4 February 2019).

21. Plain 2 Grow Systems. Available online: http://www.plain2growsystems.com/what-is-hydrogen-peroxide-h2o2--and-why-should-i-use-it-in-hydroponics--part-two (accessed on 7 February 2019).

22. El-Shinawy, M., Abd-Elmoniem, E., Abou-Hadid, A. “The Use Of Organic Manure For Lettuce Plants Grown Under Nft Conditions." Acta Horticulturae, no. 491 (1999): 315-318.

23. Churilova, Elena V., and David J. Midmore. "Vermiliquer (Vermicompost Leachate) as a Complete Liquid Fertilizer for Hydroponically-Grown Pak Choi (Brassica Chinensis L.) in the Tropics." Horticulturae 5, no. 1 (March 2019): 26.

24. Nederhoff, E. "Hydrogen peroxide for cleaning irrigation system." Commercial Grower, no. 10 (2000): 32 34.

25. Benabdellah, K., Ruiz-Lozano, J. M., Aroca, R. "Hydrogen peroxide effects on root hydraulic properties and plasma membrane aquaporin regulation in Phaseolus vulgaris." Plant Molecular Biology, no. 70 (2009), 647-661.

26. Eicher-Sodo, M., Gordon, R., \& Zheng, Y. “Characterizing the Phytotoxic Effects of Hydrogen Peroxide on Common Microgreen Species and Lettuce Cultivars." HortTechnology, no. 29 (2019), 283-289.

20 by the authors. Submitted for possible open access publication under the terms and conditions of the Creative Commons Attribution (CC BY) license (http://creativecommons.org/licenses/by/4.0/). 